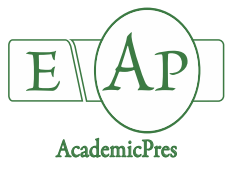

Yang L et al. (2020)

Notulae Botanicae Horti Agrobotanici Cluj-Napoca 48(1):1-13

DOI: $10.15835 /$ nbha48111761

Review Article

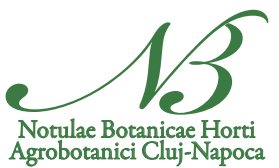

\title{
Piriformospora indica: a root endophytic fungus and its roles in plants
}

\author{
Liu YANG ${ }^{1}$, Jin-Li CAO ${ }^{1}$, Ying-Ning ZOU ${ }^{1}$, Qiang-Sheng WU ${ }^{1,2 *}$, \\ Kamil KUČA ${ }^{2}$ \\ ${ }^{1}$ Yangtze University, College of Horticulture and Gardening, Jingzhou, Hubei 434025, \\ China; 2536405387@qq.com;214073110@qq.com; zouyingning@163.com;wuqiangsh@163.com (*correspondingauthor) \\ ${ }^{2}$ University of Hradec Kralove, Faculty of Science, Department of Chemistry, Hradec Kralove 50003, Czech Republic; kamil.kuca@ubk.cz
}

\begin{abstract}
Piriformospora indica is a discovered endophytic fungus colonizing in roots of plants in 1998. The fungus can form the mycelium, mycelial roll, and pear-shaped spores in intercellular and intracellular regions of roots. The fungus colonizes various host plants and also realizes the pure culture in vitro without roots of host plants. $P$. indica shows many positive effects on host plants, including the promotion of plant growth, the enhancement of nutrient acquisition and stress tolerance, the improvement of disease resistance, and the promoted accumulation of bioactive substances. The commercial production of the fungal spores is established in bioreactor with nanostructured materials "zinc oxide" as nano embedded fungus, which provides provides changes into confers. The review simply summarized the biological characteristics of $P$. indica, physiological roles in plants, and potential utilization as a biofertilizer.
\end{abstract}

Keywords: biofertilizer; endophytic fungus; Piriformospora indica; symbiotic interaction

\section{Introduction}

In 1998, Piriformospora indica Varma, Rexer, Kost \& Franken sp. nov., an endophytic fungus of the Sebacinaceae family, was found in the rhizosphere of woody shrubs Prosopis juliflora and Zizyphus nummularia in the Tar Desert in Northwest India (Verma et al., 1998). The endophytic fungus is characterized by the formation of chlamydospore only with pear-shaped, originated from thin-walled vesicles at the tips of the hyphae (Verma et al., 1998). P. indica can grow on artificial media without plant roots and complete its life cycle. It is documented that about 150 plant species could establish symbiotic association with $P$. indica, and the fungus also colonizes non-mycorrhizal plants, including cruciferous crops plants, Arabidopsis thaliana, and so on (Liang et al., 2009).

In general, the young mycelium of $P$. indica is white and almost transparent with the diameter of 0.7-3.5 $\mu \mathrm{m}$ (Verma et al., 1998). The mycelium does not form aerial mycelium, whereas mycelium fusion can be quickly formed (Sherameti et al., 2008). The outer wall of the mycelium is separated and protruded, showing a multilayer structure. The average thickness of the mycelium wall is about $0.3 \mu \mathrm{m}$. The chlamydospore produced by mature hyphae is the key feature of $P$. indica identification, whose shape is pear-shaped. The chlamydospore cytoplasm is filled with granular substances with 8-25 nuclei (Verma et al., 1998). The chlamydospores exist in a single or in clusters, whose length and width are about $16-45 \mu \mathrm{m}$ and $10 \mu \mathrm{m}$, respectively. The spore wall 
thickness is about $0.7 \mu \mathrm{m}$, and after maturation the spore wall thickness can reach $1.5 \mu \mathrm{m}$. The chlamydospore has two layers of membranes, whilst the outer wall is pale yellow and the texture is relatively smooth.

The whole genome-sequence of $P$. indica was determined (Alga et al., 2011), having 1884 scaffolds (size $1 \mathrm{~Kb} ; \mathrm{N} 50 ; 51.83 \mathrm{~Kb}$ ) with a size of $24.98 \mathrm{Mb}$. There are 2359 overlapping groups, each of which contains a reading coverage area with an average size of 22 . The average number of exons per gene in $P$. indica is about 5.16 , with a density of 471 , a GC content of $50.68 \%$ and a repetition rate of $4.68 \%$. The content of nucleus of DNA in the $P$. indica is about $15.3-21.3 \mathrm{Mb}$. The genome contains small secretory proteins encoded by different effector genes. The conserved region at different $\mathrm{C}$-terminal heights has a gene family coding "DELD", which is related to the symbiotic nature of the bacteria. Such genomic information can provide the support for understanding the biological characteristics of the fungi and subsequent genetic studies.

Many studies had shown that $P$. indica could stimulate growth of various crop plants, accelerate nutrient acquisition, and enhance tolerance of plants to stress, thereby, having a very promising prospect for sustainable agriculture and environment (Waller et al., 2005; Liang et al., 2009). This review focuses on clarifying culture methods, interactions with plants, and potential application in agriculture for $P$. indica.

\section{Culture of Piriformospora indica}

The culture of $P$. india is usually carried out on potato glucose solid medium (PDA) or liquid medium (PDB) (Figure 1a-c). The P. indica strain is inoculated on PDA plate and activated for 14 days at $28^{\circ} \mathrm{C}$. The fermentation broth of $P$. indica is done with $50 \mathrm{~mL}$ ethyl acetate for 2 hours, and the organic phase is dried with anhydrous sodium sulfate after concentrated and steamed at $40-45^{\circ} \mathrm{C}$ and dissolved in $10 \mathrm{~mL}$ of anhydrous ethanol. The organic phase is diluted 100 times with anhydrous ethanol for application (Chen $e t$ al., 2013).P. indica has the best growth under the condition of lower stirring speed and higher working volume (Kumar et al., 2011). Increasing the growth and subsequent consumption of vegetative cells by using a certain level of glucose would enhance sporulation of P. indica (Kumar et al., 2011).

The fermentation medium with soluble starch as carbon source has a high viscosity, so that the stirring speed is higher. In shake flask culture, $P$. indica grows either in the form of pellets or as a homogeneous mycelial suspension. In bioreactors, the rapid growth of $P$. indica led to carbon depletion, ultimately modulating earlier sporulation and shorter sporogenesis. The $\mathrm{pH}$ in the late logarithmic period of $P$. indica reduces to 5.5-6.0 because of acid metabolism after full utilization of glucose. As a result, no $\mathrm{pH}$ control is needed for cultivation of $P$. indica on a complex carbon source. Sugar-deficiency strategy and soybean meal could significantly increase the biomass of $P$. indica and shorten the time needed to maximize spore production (Kumar et al., 2011). The optimum germination rate of Kelussia odoratissima plants is under the condition of spore suspension of $P$. indica (Ghabooli et al., 2019).
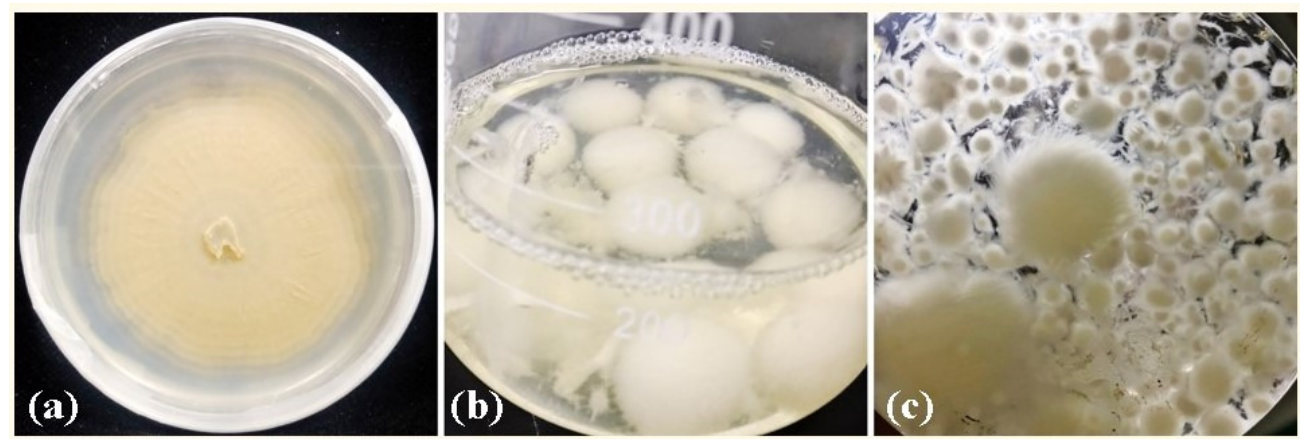

Figure 1. Culture of Piriformospora indica using potato glucose solid medium (a) and liquid medium (b and c)Root colonization of Piriformospora indica and the recognition with plant roots 


\section{Root colonization}

In the process of fungal colonization, chlamydospores of $P$. indica first produce two branched germ tubes, which can induce the formation of appressorium (Jacobs et al., 2013). These appressorium's contact with plant roots to produce invasive nails, penetrate epidermis and cortical cells to complete the initial colonization process (Jacobs et al., 2013). P. indica colonization is mainly found in near root elongation zones and seldom at the top of the roots (Kumari et al., 2003), while its hyphae are not found in the aerial part of plants at any growth stage and colonization process (Kumari et al., 2003). The colonization pattern of the fungus is closely associated with the maturity degree of cells of roots (Boller et al., 2009; Unnikumar et al., 2013). In roots, a number of spores with pear shape are found in roots (Figure $2 a-b$ ).

Qiang et al. (2012) found that during the lethal stage of $P$. indica spores' colonization, spores inhibited the transduction of endoplasmic reticulum stress signals in Arabidopsis, and eventually led to a caspasedependent cell death mediated by vacuoles. It implies that endoplasmic reticulum disfunction in roots trigger by $P$. indica is a strategy of microbes to kill plant cells.

When the PiTam1 gene cloned from P. indica was silenced, the expression of auxin decreased, and the colonization of $P$. indica in barley roots decreased, suggesting that auxin might be a promoter in the colonization of $P$. indica (Hilbert et al., 2012). Furthermore, ethylene signals are required for the symbiosis and colonization of $P$. indica, as reported by Khatabi et al. (2012), which found that ethylene enhanced the fungal colonization in roots of Arabidopsis thaliana, and the damage in ethylene signaling pathway could reduce the fungal colonization. During the interaction between plants and $P$. indica, 926 proteins with signal peptides were secreted, whilst 543 proteins were used as effector factors (Rafiqi et al., 2013). In addition, P. indica also stimulates root cytokinin concentrations during fungal colonization (Camehl et al., 2010). These results fully demonstrate that in host colonization of $P$. indica, phytohormones from both hosts and $P$. indica are stimulated to accelerate root colonization. However, more studies are needed to be conducted to analyze the changes in phytohormones in the process of $P$. indica colonization.
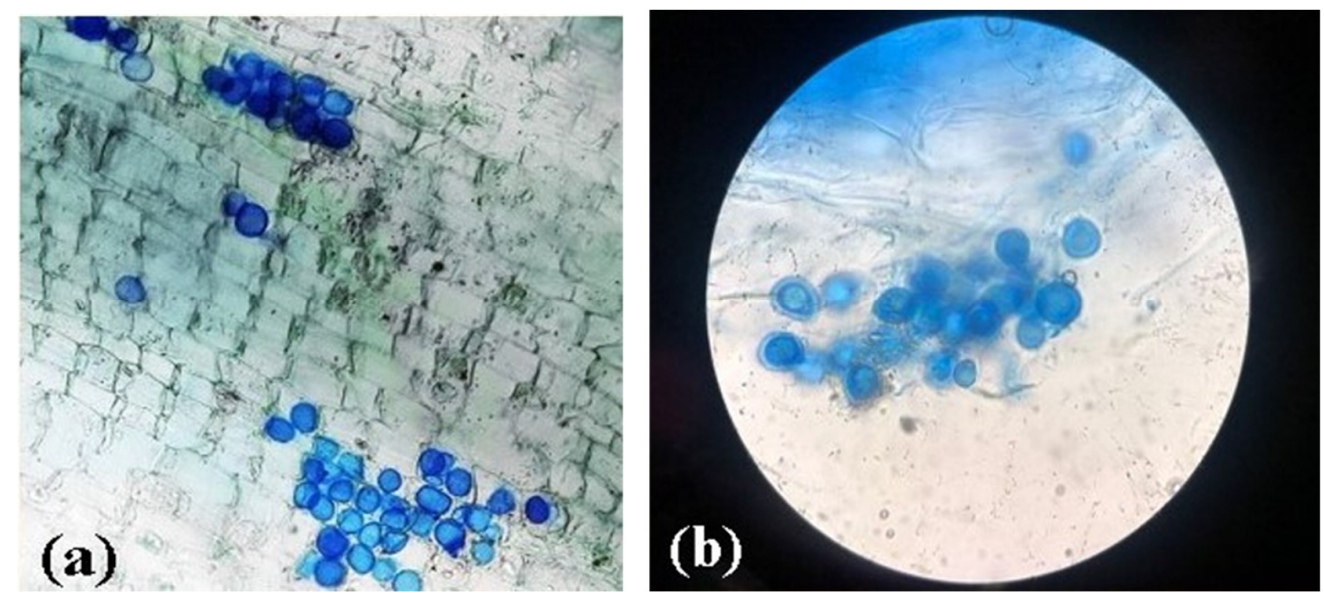

Figure 2. Root colonization of Piriformospora indica in trifoliate orange (a) and white clover (b)

\section{Host recognition and signal responses}

The recognition between $P$. indica and plant roots has signal responses. A series of host responses to symbiotic fungi are based on an efficient immune system within plants (Boller et al., 2009). Intracellular colonization of $P$. indica stimulates mode-triggered immunity (PTI) (Khatabi et al., 2012), which could be modulated by phytohormones, including ethylene, salicylic acid (SA) and jasmonic acid (JA) (Khatabi et al., 2012). The combination of both ethylene and JA blocks SA accumulation, whereas promotes the colonization 
of $P$. indica (Khatabi et al., 2012). The inactivation of some components in the ethylene pathway seriously destroys the colonization process of $P$. indica (Camehl et al., 2013). The fungus relies on JA inhibiting initial immune responses (Camehl et al., 2013). Salicylic acid thioglycoside also inhibits the growth of mycelia, while the weak ethylene signals promote the hyphal growth (Varma et al., 2001). During the interaction with roots, it is very important to maintain low ascorbic acid levels in roots, because $P$. indica is not stable in mutant plants with ascorbic acid reductase (Vadassery et al., 2009). After the fungal colonization, the levels of gibberellin, auxin and other hormones in plants also increased in varying degrees (Schäfer et al., 2009; Camehl et al., 2013). With symbiosis between the endophytic fungus $P$. indica and ethylene signal mutants of Arabidopsis thaliana, cellotriose was identified as a novel chemical mediator taking part in communications of $P$. indica and plants (Johnson et al., 2009). Schäfer et al. (2009) found that ethylene played a key role in the root colonization, and it did not cause slight up-regulation of defense responsive genes but inhibit the expression of SA signal pathwayrelated genes after the colonization of $P$. indica. On the contrary, it could inhibit the expression of SA-signalassociated genes (Schäfer et al., 2009).

The intracellular $\mathrm{Ca}^{2+}$ concentration increased significantly in the early stage of the fungal colonization of roots (Vadassery et al., 2010). The extract from cell walls of $P$. indica also caused similar reactions in Arabidopsis thaliana. It is suggested that $\mathrm{Ca}^{2+}$ may be an early signal of the fungal root colonization. $P$. indica induces lectin protein kinase in plant roots, which is a crucial factor in perception and recognition for fungal colonization (Verma et al., 2017).

\section{Roles of Piriformospora indica in host plants \\ Promotion of plant growth}

Earlier studies have demonstrated positive plant growth promotion by $P$. indica in host plants (Figure 3; Table 1) (Barazani et al., 2007; Sharma et al., 2014). The inoculation with $P$. indica increased the biomass of marine algal, and the metabolites of glutamic acid and succinic in marine algae were raised and lipid structure was improved (Bhatnagar $e$ al., 2019). In a medicinal plant Aloe vera, inoculated with $P$. indica significantly promoted biomass, plant height, root length, root number, number of buds, and chlorophyll levels. P. indica dramatically mitigates the damage on shoot and root biomass of infested cucumber plants (Atia et al., 2020). Similarly, the positive effect of the root endophyte on plant growth was reported in pistachio, beans, acacia, mung beans, and peas (Varma et al., 2001). The expression of miRNA and their target genes in orchid roots was induced by $P$. indica, whilst the target genes were involved in hormone signals, cell wall metabolism and regulatory transcription factors (Ye et al., 2014), suggesting that promotion of plant growth by $P$. indica is associated with improving the miRNA model. In addition, the fungus heavily stimulates the accumulation of auxin, andrographolide, and hexadecanoic acid, which is associated with plant growth (Bhatnagar et al., 2019). The root endophyte also promoted plant growth in Arabidopsis thaliana and tobacco seedlings, which is related with the more accumulation of nitrogen and the induced expression levels of nitrate reductase and amylo degrading enzyme genes (Sherameti et al., 2008).

The culture filtrate of $P$. indica also stimulated plant growth (Varma et al., 2001; Sharma et al., 2013; Bagde et al., 2014). Bagde et al. (2014) used the culture filtrate of $P$. indica into Aristolochia elegans, and found the enhancement in root number and length, plant height, leaf number, and plant biomass. Culture filtrate of P. indica also promoted hairy root biomass of Vigna mungo (Bagde et al., 2014) and plant growth of Artemisia annua (Sharma et al., 2013), flax plants (Kumar et al., 2012), and sunflower (Bagde et al., 2011).

In the early stage of the root endophyte colonization, intracellular $\mathrm{Ca}^{2+}$ concentrations were elevated in response to plant growth improvement (Vadassery et al., 2010). Additionally, gene expression analysis of Chinese cabbage induced by $P$. indica revealed that $P$. indica played an important role in inducing genes involved in transporting carbohydrate metabolism, hormone signaling, cell wall metabolism and root formation (Lee $e t$ 
al., 2011). Further, auxin induction is involved in the plant growth improvement by $P$. indica, as seen in Chinese cabbage with higher auxin levels from the induced expression of genes related to cell wall acidification and auxin transporter. Similarly, P. indica could interact with orthology of sugar beet Hs1 PRO-1 2 to control the early growth of tobacco seedlings. Phosphorus transporter genes in $P$. indica promote plant phosphorus uptake, because these gene expressions are induced in external mycelium (Yadav et al., 2011).

In a word, $P$. indica strongly promotes plant growth, which is associated with nutrients, auxin, miRNA model, expressions of specific genes, phytoremediator, immunomodulatory, and bio-herbicide (Khalid et al., 2019).

Table 1. The effects of Piriformospora indica on nutrient acquisition, abiotic stress tolerance, and disease resistance of part host plants

\begin{tabular}{|c|c|c|c|c|}
\hline Plants & $\begin{array}{l}\text { Responses on } \\
\text { nutrient } \\
\text { acquisition }\end{array}$ & Responses on abiotic stress & $\begin{array}{l}\text { Responses on disease } \\
\text { resistance }\end{array}$ & References \\
\hline $\begin{array}{l}\text { Arabidopsis } \\
\text { thaliana }\end{array}$ & $\mathrm{P} \uparrow$ & nitrate reductase $\uparrow$; ascorbic acid $\uparrow$ & verticillium wilt $\downarrow$ & $\begin{array}{l}\text { Sherameti et al., } \\
2005\end{array}$ \\
\hline Brassica napus & $\begin{array}{c}\mathrm{N} \uparrow ; \mathrm{P} \uparrow ; \mathrm{S} \uparrow ; \\
\mathrm{Zn} \uparrow ; \mathrm{Mn} \uparrow\end{array}$ & antioxidant enzyme activities $\uparrow$ & incidence of root rot $\downarrow$ & Chen et al., 2013 \\
\hline $\begin{array}{l}\text { Chinese } \\
\text { cabbage }\end{array}$ & $\mathrm{P} \uparrow$ & $\begin{array}{c}\text { antioxidant enzyme activities } \uparrow ; \\
\text { chlorophyll and thylakoid protein } \\
\text { degradation } \downarrow\end{array}$ & $\begin{array}{l}\text { incidence of black } \\
\text { spot } \downarrow\end{array}$ & Sun et al., 2010 \\
\hline $\begin{array}{l}\text { Cucumis } \\
\text { sativus }\end{array}$ & - & - & root knot nematode $\downarrow$ & Atia et al., 2019 \\
\hline $\begin{array}{l}\text { Hordeum } \\
\text { vulgare }\end{array}$ & - & $\begin{array}{c}\text { activity of ascorbic acid reductase } \uparrow \text {; } \\
\text { ascorbic acid } \uparrow \text {; glutathione } \uparrow\end{array}$ & $\begin{array}{l}\text { incidence of root rot } \downarrow \text {; } \\
\text { powdery mildew } \\
\text { fungus } \downarrow\end{array}$ & $\begin{array}{c}\text { Waller et al., } \\
\text { 2005; Ghaffari et } \\
\text { al., } 2019\end{array}$ \\
\hline $\begin{array}{l}\text { Nicotiana } \\
\text { tabacum }\end{array}$ & $\mathrm{N} \uparrow ; \mathrm{P} \uparrow ; \mathrm{Zn} \uparrow$ & $\begin{array}{l}\text { chlorophyll } \uparrow \text {; indole acetic acid } \uparrow ; \\
\text { catalase } \uparrow ; \text { superoxide dismutase } \uparrow\end{array}$ & $\begin{array}{c}\text { incidence of } \\
\text { herbivorous insects } \downarrow\end{array}$ & $\begin{array}{l}\text { Abdelaziz et al., } \\
2019\end{array}$ \\
\hline $\begin{array}{l}\text { Triticum } \\
\text { aestivum }\end{array}$ & $\mathrm{N} \uparrow ; \mathrm{P} \uparrow$ & $\begin{array}{c}\text { ascorbic acid } \uparrow \text {; acid reductase } \uparrow \text {; } \\
\text { catalase } \uparrow \text {; deoxyascorbic } \uparrow ; \\
\text { glutathione reductase } \uparrow ; \\
\text { peroxidase } \uparrow\end{array}$ & fusarium $\downarrow$ & $\begin{array}{l}\text { Baltruschat et al., } \\
2008\end{array}$ \\
\hline Zea mays & $\mathrm{P} \uparrow$ & $\begin{array}{c}\text { deoxyascorbic acid reductase } \uparrow ; \\
\text { glutathione } \uparrow \text { oxidative potential } \uparrow ; \\
\text { abscisic acid } \uparrow \text {; auxin } \uparrow \text {; cytokinins } \uparrow ; \\
\text { salicylic acid } \uparrow\end{array}$ & incidence of root rot $\downarrow$ & $\begin{array}{l}\text { Stein et al., 2008; } \\
\text { Zhang et al., } 2018\end{array}$ \\
\hline
\end{tabular}

Note: The symbol “ $\uparrow$ " and " $\downarrow$ ” means the significant increase and the significant decrease in the parameter after

Piriformospora indica colonization. The symbol "-" means that author did not analyse the change in the parameter

\section{Increase of nutrient acquisition}

There are generally two ways for plants to absorb P directly from roots and from symbiotic fungi. In the interaction between $P$. indica and barley, the fungus increased the maximum use of $\mathrm{P}$ (Waller et al., 2005) and accelerated the transformation from insoluble and agglutinated or complex forms of $\mathrm{P}$ into soluble $\mathrm{P}$ in soil (Singh et al., 2000). In the colonization of barley, tobacco and mung bean, $P$. indica did not increase the content of $\mathrm{N}$ and $\mathrm{P}$ in plants, although it promoted the plant growth of plants (Achatz et al., 2010). In contrast, the fungal colonization significantly changed $\mathrm{N}, \mathrm{P}$ and $\mathrm{K}$ concentrations in lentils and chickpeas these plants (Nautiyal et al., 2010).P. indica heavily increased phosphatase activities and expression levels of ACP5 in roots of Brassica napus to accelerate P acquisition (Wu et al., 2018). In addition, the colonization of $P$. indica could 
6

alleviate the damage caused by $\mathrm{Fe}$ and $\mathrm{Cu}$ deficit in sugarcane (Table 1) (Gosal et al., 2010). The root endophyte colonization increased N, P, S, Zn, and Mg levels in rapeseed and N, P, and Zn concentrations in tomato (Sarma et al., 2011; Chen et al., 2013). P. indica also increased the content of radiolabeled P in Arabidopsis thaliana and Anthurium spp., which originates from the up-regulated expression of $\mathrm{P}$ transporter (Sherameti et al., 2008; Lin et al., 2019). Fungal PiMgT1 transporter of $\mathrm{Mg}$ was involved in the absorption of $\mathrm{Mg}$ in wheat exposed to $\mathrm{Zn}$ deficiency stress (Prasad $e t$ al., 2018). In addition, $P$. indica up-regulated NADH-dependent nitrate reductase gene expressions to promote $\mathrm{N}$ acquisition (Serfling et al., 2007).

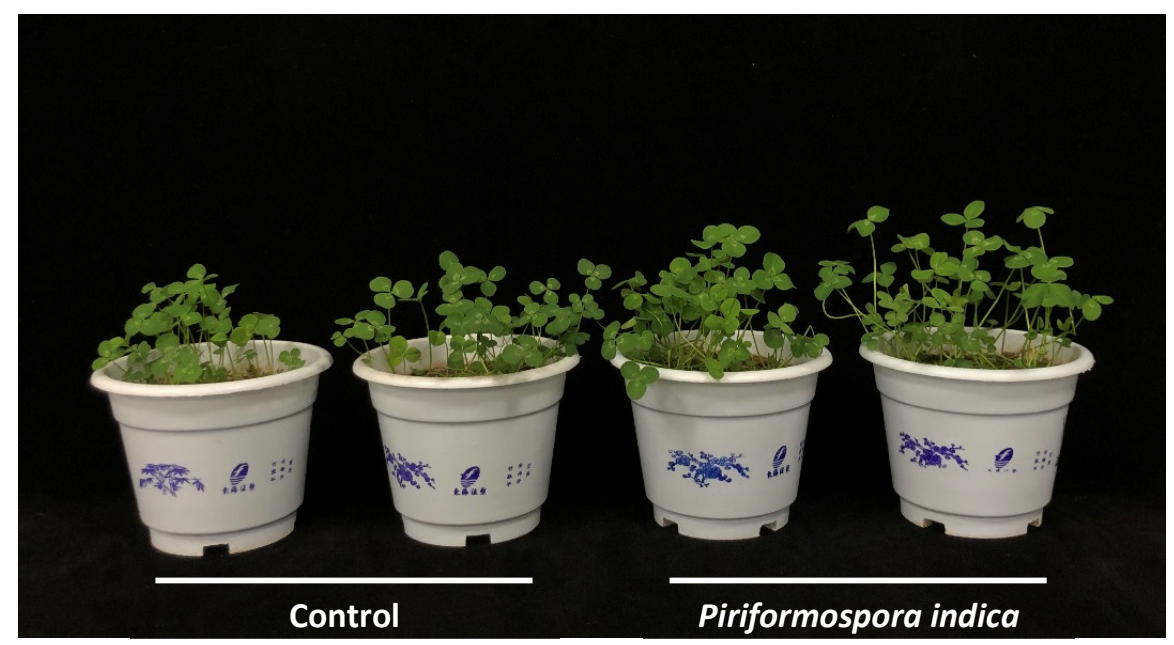

Figure 3. A positive effect of Piriformospora indica on plant growth response of white clover after 26 days of the fungal inoculation

\section{Enhancement of stress tolerance}

In addition to plant growth and nutrient acquisition, $P$. indica also enhances stress tolerance of plants (Table 1). For example, $P$. indica enhanced drought tolerance of Chinese cabbage through increasing antioxidant enzyme activity, reducing chlorophyll and thylakoid protein degradation, and alleviating photosynthetic efficiency decline (Sun et al., 2010). Similarly, chlorophyll, indole acetic acid, catalase, superoxide dismutase and $L e N H X I$ expression by colonization of $P$. indica were increased under salt stress (Abdelaziz et al., 2019). Under adverse conditions, P. indica increased the levels of photosynthesis, antioxidant defense systems and energy transfer proteins to tolerate the negative effect (Ghabooli et al., 2013). In barley, the activity of ascorbic acid reductase and the content of both ascorbic acid and glutathione increased after inoculation with $P$. indica under salt stress (Waller et al., 2005). Likewise, colonization of $P$. indica conferred superior drought adaptation of barley through enhanced activity of both photosystems and electron transfer chains and promoted accumulation of photorespiration proteins (Ghaffari et al., 2019). Under drought stress, $P$. indica stimulated gene expression in maize associated with hormone functions, including abscisic acid, auxin, salicylic acid and cytokinins (Zhang et al., 2018). Colonization of $P$. indica in wheat roots could alleviate membrane lipid peroxidation and fatty acid desaturation in leaf tissues under salt stress, and increased the content of ascorbic acid and the activity of ascorbic acid peroxidase, catalase, deoxyascorbic acid reductase and glutathione reductase in root tissues under salt stress (Baltruschat $e t$ al., 2008). The colonization of $P$. indica in Centella asiatica exposed to $P$ deficit showed a positive effect through the increase in acid/alkaline phosphatase activity, total phenolics and superoxide dismutase activity (Jisha et al., 2019). In rape, Chen et al. (2013) reported that the root endophyte had a significant improvement in drought tolerance, because of lower plasma membrane permeability and higher proline content, antioxidant enzyme activities, and drought-related 
responsive gene expressions. Moreover, an increase in antioxidant enzymes activities were found in Medicago truncatula by the endophyte under high salinity conditions (Li et al., 2019). Sarma et al. (2018) analyzed the effect of $P$. indica on tomato, and revealed that the fungus increased tomato plant growth yield and prevented the occurrence of fusarium wilt. Under the conditions of water deficit and drought, protein analysis of barley leaves inoculated with $P$. indica showed that the fungus increased the level of proteins involved in photosynthesis, antioxidant defense system and energy transmission (Ghabooli et al., 2013). P. indica inoculation increased the expression level of a RNA editing factor to enhance the plant's capability to salinity stress (Hassani et al., 2019).

Recently, Ghaffari et al. (2018) used the proteomic and metabolomic technologies to reveal the molecular basis of barley plants inoculated with $P$. indica. They found that the fungal inoculation could readjust plant metabolites and proteome, redistributes resources of host plants, and keeps aquaporin protein activity in response to water deficit, which confers better drought tolerance in plants.

\section{Enhancement of disease resistance}

$P$. indica not only improved the ability of plants to resist root diseases, but also improve the ability of plants to resist leaf diseases (Table 1) (Ghaffari et al., 2018). Rabiey et al. (2015) found that $P$. indica had no direct antagonistic effect on fusarium in vitro, but the wheat inoculated with $P$. indica found few signs of brown rot, compared with uninoculated wheat. The phenomenon was related with higher ascorbic acid and glutathione levels and better antioxidant enzyme activities (Rabiey et al., 2015). The colonization of $P$. indica in cucumber also significantly increased chlorophyll levels and alleviated the negative effects of root knot nematode (Meloidogyne incognita) on photosynthesis (Atia et al., 2020). The inoculation of $P$. indica significantly improved the resistance of maize to root rot, because of greater activities of catalase, glutathione reductase, glutathione transferase and superoxide dismutase (Kumar et al., 2009). Nassimi and Taheri (2017) found that $P$. indica increased the rice biomass and also delayed the infection process of $R$. solani, resulting in the decrease of sheath blight severity. P. indica also increased the $\mathrm{pH}$ in the axoplast of leaves in barley infected by powdery mildew fungus, which further induced the expression levels of defensive genes and the accumulation of resistance-related substances in plants (Felle et al., 2009). Therefore, the systemic resistance induced by $P$. indica may be related to the change of plastid $\mathrm{pH}$.

P. indica could significantly reduce the expansion of verticillium wilt in Arabidopsis thaliana in vitro after verticillium wilt infection, and other signals of spores were involved in the defense of Arabidopsis against verticillium wilt (Sun et al., 2010). Trzewik et al. (2020) successfully use $P$. indica as a possibility of biological protection against Phytophthora in rhododendron plants. P. indica induced resistance to powdery mildew in mutants of JA signaling pathway, and did not induce the transcript levels of defensive genes involved in SA signaling pathways (Stein et al., 2008).

\section{Promotion of bioactive substance accumulation}

$P$. indica has a critical role in promoting bioactive substance accumulation of plants. The aristolochic acid concentrations in leaves of Aristolochia elegans were heavily induced by the fungal culture filtrate (Bagde et al., 2014), indicating an important role in accelerating bioactive substances. In Artemisia annua, the culture filtrate of $P$. indica comparatively increased artemisinin levels, an antimalarial compound (Sharma et al., 2013). The increase in artemisinin content caused by inoculation with $P$. indica may be due to the enhanced biosynthesis of the artemisinin after the colonization of the fungus $P$. indica. Other studies also indicated that $P$. indica increased lignan concentrations of Vigna mungo (Kumar et al., 2012) and oil contents of sunflower (Bagde et al., 2014). These results confirmed the positive influence of $P$. indica in bioactive substance accumulation of plants. However, more studies will need to clarify the causal relationship. 
Piriformospora indica: a potential fertilizer in the future of agriculture

It was found that $P$. indica and Bacillus brevis could promote black jelly beans more obviously than $P$. indica alone (Anith et al., 2015). PDB is a commonly used medium for $P$. indica fermentation, whereas $B$. pumilus cannot grow in PDB, which limits the development of $P$. indica compound fertilizer with $B$. pumilus. $P$. indica fertilizer can be fermented by coconut water, and thus economical coconut water can be used to coculture $P$. indica and B.pumilus, providing a possibility for mass production of $P$. indica (Tripathi et al., 2015).

Compared with liquid bacteria, $P$. indica fertilizer has incomparable advantages in spore efficacy, cell viability, and transportation. Tripathi $e t$ al. (2015) explored $P$. indica as a carrier of biological agents. They used the mixture of $P$. indica and talc powder at $5 \%$ mass ratio as carriers that is the most stable and effective. The mixture maintains $108 \mathrm{CFU} / \mathrm{g}$ at $30^{\circ} \mathrm{C}$, and the validity period of spores can be extended to 180 days.

Varma et al. (2001) observed that the fermentation broth of $P$. indica was filtered through double-layer gauze to obtain $P$. indica mycelium, and magnesium sulfite was used as a carrier mixed with mycelium using $2 \%$ of the mass ratio, whose activity was the most effective and stable.

To obtain the commercial production of spores, Varma (2017) proposed that $P$. indica was cultivated in a $7 \mathrm{~L}$ batch bioreactor with nanostructured materials "zinc oxide" as nanoembedded fungus. Such protocol can provide $9.25 \times 10^{9}$ spores $/ \mathrm{mL}$ with zinc oxide nanorods. This will confer a kind of innovative technique for providing a path for agricultural application

\section{Conclusions}

$P$. indica has a wide range of colonization in plants and shows various functions, such as promoting plant growth, enhancing stress tolerance and disease resistance, and accelerating nutrient acquisition and bioactive substance accumulation (Figure 4). In addition, the effective colonization of $P$. indica improves rhizosphere microorganisms' activity to reduce the toxicity of heavy metal-contaminated soil, or induces expression of resistant genes (Zhu et al., 2019). Compared with mycorrhizal fungi, $P$. indica has obvious advantages in culture in vitro. Based on this, more and more attention has been paid to $P$. indica in sustainable agriculture and environment. For example, Liu et al. (2019) established a co-culture system between $P$. indica and oncidium plants in G10 medium in vitro to enhance plant growth. Li et al. (2019) used $P$. indica plugs and chlamydospora suspension into rooting medium of banana seedlings in vitro and found the fungal strongly stimulated plant growth and shorten the rooting time. This result provides a valuable idea for shortening the time of tissue culture in plants that are difficult to rooting. However, due to lack of understanding molecular mechanisms in the interaction of $P$. indica and plants, the application of $P$. indica has still been limited (Shahollari et al., 2007). $P$. indica can be used as potential biological hardening agent for endangered micro propagated plants such as Picrorbiza kurroa to improve the survival rate (Das et al., 2017).

Additionally, growth conditions and environments influence the interaction between $P$. indica and plants and the production and application of commercial inoculants, which need to be further studied. The fungus can be transported over long distances as inoculants, and can be produced in large quantities by economically viable methods such as nano-method, promising vigor growth for crops grown in poor soils. $P$. indica also enhances disease resistance of plants, which would reduce the use of pesticides, thereby, mitigating the pressure on the environment and improving food safety (Lou et al., 2007). 


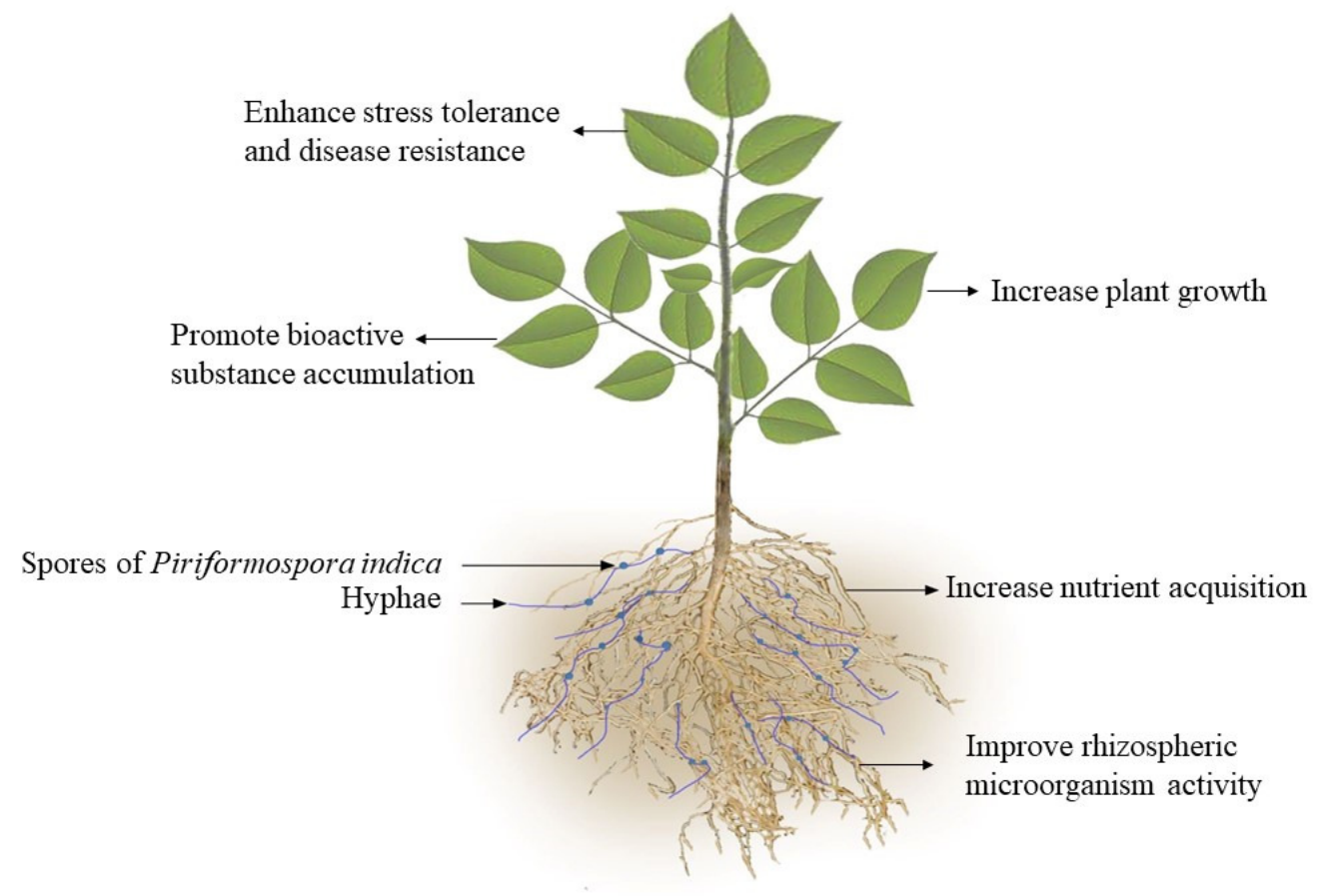

Figure 4. The positive effects of Piriformospora indica on plants

An important characteristic of $P$. indica is the comparative improvement of plant growth in various crops, while the underlying mechanisms are still unclear, relative to mycorrhizal fungi (He et al., 2019, 2020; Wu et al., 2019; Zhang et al., 2020; Zou et al., 2019). On the other hand, the fungus also enhances the tolerance of abiotic stress in plants, whereas the signal mechanisms and pathways of the increased antioxidant defense systems remain to be elucidated. The interaction between $P$. indica and other bacteria/fungi in improving plant growth still needs to be studied.

\section{Acknowledgements}

This study was supported by the Plan in Scientific and Technological Innovation Team of Outstanding Young Scientists, Hubei Provincial Department of Education (T201604) and the Hubei Agricultural Science and Technology Innovation Action Project.

\section{Conflict of Interests}

The authors declare that there are no conflicts of interest related to this article. 


\section{References}

Abdelaziz ME, Abdelsattar M, Abdeldaym EA, Atia MA, Mahmoud AWM, Saad MM, Hirt H (2019). Piriformospora indica alters $\mathrm{Na}^{+} / \mathrm{K}^{+}$homeostasis, antioxidant enzymes and LeNHX1 expression of greenhouse tomato grown under salt stress. Scientia Horticulturae 256:108532.

Achatz B, von Rüden S, Andrade D, Neumann E, Pons-Kühnemann J, Kogel KH, Walle F (2010). Root colonization by Piriformospora indica enhances grain yield in barley under diverse nutrient regimes by accelerating plant development. Plant and Soil 333(1-2):59-70.

Alga Z, Urs L, Güldener U, Ulrich U (2011). Endophytic life strategies decoded by genome and transcriptome analyses of the mutualistic root symbiont Piriformospora indica. PLoS Pathogens 7(10):e1002290.

Anith KN, Sreekumar A, Sreekumar J (2015). The growth of tomato seedlings inoculated with co-cultivated Piriformospora indica and Bacilluspumilus. Symbiosis 65(1):9-16.

Atia MAM, Abdeldaym EA, Abdelsattar M, Ibrahim DSS, Saleh I, Elwahab MA, Osman GH, ... Abdelaziz ME (2019). Piriformospora indica promotes cucumber tolerance against root-knot nematode by modulating photosynthesis and innate responsive genes. Saudi Journal of Biological Sciences 27(1):279-287.

Bagde US, Prasad R, Varma A (2011). Influence of culture filtrate of Piriformospora indica on growth and yield of seed oil in Helianthus annus. Symbiosis 53(2):83-88.

Bagde US, Prasad R, Varma A (2014). Impact of culture filtrate of Piriformospora indica on biomass and biosynthesis of active ingredient aristolochic acid in Aristolochia elegans Mart. International Journal of Biology 6(1):29-37.

Baltruschat H, Fodor J, Harrach BD, Niemczyk E, Barna B, Gullner G, Zuccaro A (2008). Salt tolerance of barley induced by the root endophyte Piriformospora indica is associated with a strong increase in antioxidants. New Phytologist 180(2):501-510.

Barazani O, von Dahl CC, Baldwin IT (2007). Sebacina vermifera promotes the growth and fitness of Nicotiana attenuata by inhibiting ethylene signaling. Plant Physiology 144(2):1223-1232.

Bhatnagar VS, Bandyopadhyay P, Rajacharya GH, Sarkar S, Poluri KM, Kumar S (2019). Amelioration of biomass and lipid in marine alga by an endophytic fungus Piriformospora indica. Biotechnology for Biofuels 12(1):12-176.

Boller T, Felix G (2009). A renaissance of elicitors: perception of microbe-associated molecular patterns and danger signals by pattern-recognition receptors. Annual Review of Plant Biology 60(1):379-406.

Camehl I, Sherameti I, Seebald E, Johnson JM, Oelmüller R (2013). Role of defense compounds in the beneficial interaction between Arabidopsis thaliana and Piriformospora indica. In: Varma A, Kost G, Oelmüller R. (eds) Piriformospora indica. Soil Biology, vol 33. Springer, Berlin, Heidelberg pp 239-250.

Camehl I, Sherameti I, Venus Y, Bethke G, Varma A, Lee J, Oelmüller R (2010). Ethylene signalling and ethylene-targeted transcription factors are required to balance beneficial and nonbeneficial traits in the symbiosis between the endophytic fungus Piriformospora indica and Arabidopsis thaliana. New Phytologist 185(4):1062-1073.

Chen YY, Lou BG, Gao QK, Lin FC (2013). Preliminary study on mechanisms of drought resistance in Brassica napus L. conferred by Piriformospora indica. Journal of Agricultural Biotechnology 21(3):272-281.

Das A, Tripathi S, Varma A (2017). Use of Piriformospora indica as potential biological hardening agent for endangered micropropagated Picrorbiza kurroa Royel ex Benth. Proceedings of the National Academy of Sciences, India Section B: Biological Sciences 87(3):799-805.

Felle HH, Waller F, Molitor A (2009). The mycorrhiza fungus Piriformospora indica induces fast root-surface $\mathrm{pH}$ signaling and primes systemic alkalinization of the leaf apoplast upon powdery mildew infection. Molecular Plant-Microbe Interactions 22(9):1179-1185.

Ghabooli M, Khatabi B, Ahmadi FS, Sepehri M, Mirzaei M, Amirkhani A, Salekdeh GH (2013). Proteomics study reveals the molecular mechanisms underlying water stress tolerance induced by Piriformospora indica in barley. Journal of Proteomics 94:289-301.

Ghabooli M, Rostami M, Kaboosi E (2019). Combination effect of Piriformospora indica, chilling and gibberellic acid on seed germination traits of Kelussia odoratissima Mozaff. Journal of Medicinal Plants and By-product 8(1):33-40. 
Ghaffari MR, Mirzaei M, Ghabooli M, Khatabi B, Wu YQ, Zabet-Moghaddam M, ... Salekdeh GH (2019). Root endophytic fungus Piriformospora indica improves drought stress adaptation in barley by metabolic and proteomic reprogramming. Environmental and Experimental Botany 157:197-210.

Gosal SK, Karlupia A, Gosal SS (2010). Biotization with Piriformospora indica and Pseudomonas fluorescens improves survival rate, nutrient acquisition, field performance and saponin content of micropropagated Chlorophytum sp. Indian Journal of Biotechnology 9(3):289-297.

Hassani D, Khalid M, Huang D, Zhang YD (2019). Morphophysiological and molecular evidence supporting the augmentative role of Piriformospora indica in mitigation of salinity in Cucumis melo L. Acta Biochimica et Biophysica Sinica 51(3):301312.

He JD, Dong T, Wu HH, Zou YN, Wu QS, Kuča K (2019). Mycorrhizas induce diverse responses of root TIP aquaporin gene expression to drought stress in trifoliate orange. Scientia Horticulturae 243:64-69.

He JD, Zou YN, Wu QS, Kuča K (2020). Mycorrhizas enhance drought tolerance of trifoliate orange by enhancing activities and gene expression of antioxidant enzymes. Scientia Horticultureae 262:108745.

Hilbert M, Voll LM, Ding Y (2012). Indole derivative production by the root endophyte Piriformospora indica is not required for growth promotion but for biotrophic colonization of barley roots. New Phytologist 196(2):520-534.

Jacobs S, Kogel KH, Patrick Schäfer (2013). Root-based innate immunity and its suppression by the mutualistic fungus Piriformospora indica. In: Varma A, Kost G, Oelmuller R (Eds). Piriformospora indica. Soil Biology, vol 33. Springer, Berlin, Heidelberg pp 223-237.

Jisha S, Anith KN, Sabu KK (2019). The protective role of Piriformospora indica colonization in Centella asiatica (L.) in vitro under phosphate stress. Biocatalysis and Agricultural Biotechnology 19:101088.

Johnson JM, Thürich J, Petutschnig EK, Altschmied L, Meichsner D, Sherameti I, Furch AC (2018). A poly (A) ribonuclease controls the cellotriose-based interaction between Piriformospora indica and its host Arabidopsis. Plant Physiology 176(3):2496-2514.

Khalid M, Rahman SU, Huang DF (2019). Molecular mechanism underlying Piriformospora indica-mediated plant improvement/protection for sustainable agriculture. Acta Biochimica et Biophysica Sinica 51(3):229-242.

Khatabi B, Molitor A, Lindermayr C (2012). Ethylene supports colonization of plant roots by the mutualistic fungus Piriformospora indica. PLoS ONE 7(4):e35502.

Kumar M, Yadav V, Tuteja N (2009). Antioxidant enzyme activities in maize plants colonized with Piriformospora indica. Microbiology 155(3):780-790.

Kumar V, Rajauria G, Sahai V (2012). Culture filtrate of root endophytic fungus Piriformospora indica promotes the growth and lignan production of Linum album hairy root cultures. Process Biochemistry 47(6):901-907.

Kumar V, Sahai V, Bisaria VS (2011). High-density spore production of Piriformospora indica, a plant growth-promoting endophyte, by optimization of nutritional and cultural parameters. Bioresource Technology 102(3):3169-3175.

Kumar V, Sarma MVRK, Saharan K (2012). Effect of formulated root endophytic fungus Piriformospora indica and plant growth promoting rhizobacteria Fluorescent pseudomonads R62 and R81 on Vigna mungo. World Journal of Microbiology \& Biotechnology 28(2):595-603.

Kumari R, Kishan H, Bhoon YK (2003). Colonization of cruciferous plants by Piriformospora indica. Current Science 85(12):1672-1674.

Lee YC, Johnson JM, Chien CT (2011). Growth promotion of Chinese cabbage and Arabidopsis by Piriformospora indica is not stimulated by mycelium-synthesized auxin. Molecular Plant-Microbe Interactions 24(4):421-431.

Li D, Mensah RA, Liu F, Tian N, Qi Q, Yeh KW, ... Lai ZX (2019). Effects of Piriformospora indica on rooting and growth of tissue-cultured banana (Musa acuminate cv. 'Tianbaojiao') seedlings. Scientia Horticulturae 257:108649.

Liang C, Wang R (2009) Anatomical and physiological divergences and compensatory effects in two Leymus chinensis (Poaceae) ecotypes in Northeast China. Agriculture Ecosystems \& Environment 134(1-2):46-52.

Lin HF, Xiong J, Zhou HM, Chen CM, Lin FZ, Xu XM, Yeh KW (2019). Growth promotion and disease resistance induced in Anthurium colonized by the beneficial root endophyte Piriformospora indica. BMC Plant Biology 19(1):40.

Liu HC, Li MJ, Jin L, Tian DQ, Zhu KY, Zhang JQ, ... Tang C (2019). Effects of Piriformospora indica on growth of oncidium seedling in vitro. Zhejiang Agriculture Sciences 60(4):642-645. 
Lou BG, Sun C, Cai DD (2007). P. indica with multiple functions and its application prospects. Acta Phytophylacica Sinica 34(6):653-656.

Nassimi Z, Taheri P (2017). Endophytic fungus Piriformospora indica induced systemic resistance against rice sheath blight via affecting hydrogen peroxide and antioxidants. Biocontrol Science and Technology 27(2):252-267.

Nautiyal CS, Chauhan PS, DasGupta SM, Seem K, Varma A, Staddon WJ (2010). Tripartite interactions among Paenibacillus lentimorbus NRRL B-30488, Piriformospora indica DSM 11827, and Cicer arietinum L. World Journal of Microbiology and Biotechnology 26(8):1393-1399.

Prasad D, Verma N, Bakshi M, Narayan OP, Singh AK, Dua M, Johri AK (2018). Functional characterization of a magnesium transporter of root endophytic fungus Piriformospora indica. Frontiers in Microbiology 9:3231.

Qiang X, Zechmann B, Reitz MU (2012). The mutualistic fungus Piriformospora indica colonizes Arabidopsis roots by inducing an endoplasmic reticulum stress-triggered caspase-dependent cell death. Plant Cell 24(2):794-809.

Rabiey M, Ullah I, Shaw MW (2015). The endophytic fungus Piriformospora indica protects wheat from Fusarium crown rot disease in simulated UK autumn conditions. Plant Pathology 64(5):1029-1040.

Rafiqi M, Jelonek L, Akum NF (2013). Effector candidates in the secretome of Piriformospora indica, a ubiquitous plantassociated fungus. Frontiers in Plant Science 4:228.

Sarma MVRK, Kumar V, Saharan K, Srivastava R, Sharma AK, Prakash A, Bisaria VS (2011). Application of inorganic carrierbased formulations of fluorescent pseudomonads and Piriformospora indica on tomato plants and evaluation of their efficacy. Journal of Applied Microbiology 111(2):456-466.

Schäfer P, Pfiffi S, Voll LM, Zajic D, Chandler PM, Waller F, Kogel KH (2009). Manipulation of plant innate immunity and gibberellin as factor of compatibility in the mutualistic association of barley roots with Piriformospora indica. The Plant Journal 59(3):461-474.

Serfling A, Wirsel SG, Lind V (2007). Performance of the biocontrol fungus Piriformospora indica on wheat under greenhouse and field conditions. Phytopathology 97(4):523-531.

Shahollari B, Vadassery J, Varma A (2007). A leucine-rich repeat protein is required for growth promotion and enhanced seed production mediated by the endophytic fungus Piriformospora indica in Arabidopsis thaliana. Plant Journal 50(1):1-13.

Sharma G, Agrawal V (2013). Marked enhancement in the artemisinin content and biomass productivity in Artemisia annua L. shoots co-cultivated with Piriformospora indica. World Journal of Microbiology \& Biotechnology 29(6):1133-1138.

Sharma P, Kharkwal AC, Abdin MZ (2014). Piriformospora indica improves micropropagation, growth and phytochemical content of Aloe vera L. plants. Symbiosis 64(1):11-23.

Sherameti I, Venus Y, Drzewiecki C, Tripathi S, Dan VM, Nitz I, Oelmüller R (2008). PYK10, a $\beta$-glucosidase located in the endoplasmatic reticulum, is crucial for the beneficial interaction between Arabidopsis thaliana and the endophytic fungus Piriformospora indica. Plant Journal 54(3):428-439.

Singh A, Sharma J, Rexer KH (2000). Plant productivity determinants beyond minerals, water and light: Piriformospora indica, a revolutionary plant growth promoting fungus. Current Science 79(11):1548-1554.

Stein E, Molitor A, Kogel KH, Waller F (2008). Systemic resistance in Arabidopsis conferred by the mycorrhizal fungus Piriformospora indica requires jasmonic acid signaling and the cytoplasmic function of NPR1. Plant and Cell Physiology 49(11):1747-1751.

Sun C, Johnson JM, Cai D (2010). Piriformospora indica confers drought tolerance in Chinese cabbage leaves by stimulating antioxidant enzymes, the expression of drought-related genes and the plastid-localized CAS protein. Journal of Plant Physiology 167(12):1009-1017.

Tripathi S, Das A, Chandra A (2015). Development of carrier-based formulation of root endophyte Piriformospora indica and its evaluation on Phaseolus vulgaris L. World Journal of Microbiology and Biotechnology 31(2):337-344.

Trzewik A, Maciorowski R, Klocke E, Orlikowska T (2020). The influence of Piriformospora indica on the resistance of two rhododendron cultivars to Phytophthora cinnamomi and P. plurivora. Biological Control 140:104-121.

Unnikumar KR, Sree KS, Varma A (2013). Piriformospora indica: a versatile root endophytic symbiont. Symbiosis 60(3):107113.

Vadassery J, RanfS, Drzewiecki C (2010). A cell wall extract from the endophytic fungus Piriformospora indica promotes growth of Arabidopsis seedlings and induces intracellular calcium elevation in roots. Plant Journal 59(2):193-206. 
Vadassery J, Tripathi S, Prasad R, Varma A, Oelmüller R (2009). Monodehydroascorbate reductase 2 and dehydroascorbate reductase 5 are crucial for a mutualistic interaction between Piriformospora indica and Arabidopsis. Journal of Plant Physiology 166(12):1263-1274.

Varma A (2017). Cultivation of Piriformospora indica with nanomaterial in bioreactor: In: Varma A, Prasad R, Tuteja N (2017). (eds) Mycorrhiza: Eco-physiology, secondary metabolites, nanomaterials. Springer, Cham, pp 303-310.

Varma A, Singh A, Sudha Sahay NS, Sharma J, Roy A, Kumari M, ... Kranner I (2001). Piriformospora indica: an axenically culturable mycorrhiza-like endosymbiotic fungus. In: Hock B. (2001) (eds) Fungal Associations. The mycota (A comprehensive treatise on fungi as experimental systems for basic and applied research), vol 9. Springer, Berlin, Heidelberg pp 125-150.

Verma A, Praveen K, Kailash U (2017). Lectin protein kinase is induced in plant roots in response to the endophytic fungus, Piriformospora indica. Plant Molecular Biology Reporter 35:323-332.

Verma S, Varma A, Rexer KH, Hassel A, Kost G, Sarbhoy A, ... Franken P (1998). Piriformospora indica, gen. et sp. nov., a new root-colonizing fungus. Mycologia 90:896-903.

Waller F, Achatz B, Baltruschat H (2005). The endophytic fungus Piriformospora indica reprograms barley to salt-stress tolerance, disease resistance, and higher yield. Proceedings of the National Academy of Sciences of the United States of America 102(38):13386-13391.

Wu MY, Wei Q, Xu L, Li HZ, Oelmüller R, Zhang WY (2018). Piriformospora indica enhances phosphorus absorption by stimulating acid phosphatase activities and organic acid accumulation in Brassica napus. Plant and Soil 432(1-2):333344.

Wu QS, He JD, Srivastava AK, Zou YN, Kuča K (2019). Mycorrhizas enhance drought tolerance of citrus by altering root fatty acid compositions and their saturation levels. Tree Physiology 39:1149-1158.

Yadav V, Kumar M, Deep DK, Kumar H (2011). A phosphate transporter from the root endophytic fungus Piriformospora indica plays a role in phosphate transport to the host plant. Plant Signaling \& Behavior 285(5):26532-26544.

Ye W, Shen CH, Lin YL, Chen PJ, Xu XM, Oelmüller R, ... Lai ZX (2014). Growth promotion-related miRNAs in Oncidium orchid roots colonized by the endophytic fungus Piriformospora indica. PLoS ONE 9(1):e84920.

Zhang F, Zou YN, Wu QS, Kuča K (2020). Arbuscular mycorrhizas modulate root polyamine metabolism to enhance drought tolerance of trifoliate orange. Environmental and Experimental Botany 171:103926.

Zhang WY, Wang J, Xu L, Wang AA, Huang L, Du HW, ... Oelmüller R (2018). Drought stress responses in maize are diminished by Piriformospora indica. Plant Signaling \& Behavior 13(1):e1414121.

Zhu PY, Han B, Wang XY, Zhang ZH, Chang LL (2019). Study on the remediation of cadmium pollution in soil by combination of Medicago sativa and Piriformospora indica. Environmental Science \& Technology 42(6):21-27.

Zou YN, Wu HH, Giri B, Wu QS, Kuča K (2019). Mycorrhizal symbiosis down-regulates or does not change root aquaporin expression in trifoliate orange under drought stress. Plant Physiology and Biochemistry 144:292-299.
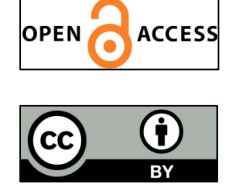

The journal offers free, immediate, and unrestricted access to peer-reviewed research and scholarly work. Users are allowed to read, download, copy, distribute, print, search, or link to the full texts of the articles, or use them for any other lawful purpose, without asking prior permission from the publisher or the author.

License - Articles published in Notulae Botanicae Horti Agrobotanici Cluj-Napoca are Open-Access, distributed under the terms and conditions of the Creative Commons Attribution (CC BY 4.0) License. (c) Articles by the authors; UASVM, Cluj-Napoca, Romania. The journal allows the author(s) to hold the copyright/to retain publishing rights without restriction. 